\title{
An Unformed Chip Thickness Approach to Study the Influence of Process Vibration on Machining Performance in Milling
}

\author{
Miaoxian Guo \\ University of Shanghai for Science and Technology \\ Jianming Wang \\ University of Shanghai for Science and Technology \\ Weicheng Guo ( $\nabla$ wcguo@usst.edu.cn ) \\ University of Shanghai for Science and Technology \\ Jin Liu \\ University of Shanghai for Science and Technology \\ Xiaohui Jiang \\ University of Shanghai for Science and Technology
}

\section{Research Article}

Keywords: Amplitude-frequency characteristics, Milling Vibration, Unformed chip thickness, milling force, milling temperature

Posted Date: October 25th, 2021

DOl: https://doi.org/10.21203/rs.3.rs-999925/v1

License: (1) This work is licensed under a Creative Commons Attribution 4.0 International License. Read Full License

Version of Record: A version of this preprint was published at The International Journal of Advanced Manufacturing Technology on March 29th, 2022. See the published version at https://doi.org/10.1007/s00170-022-09088-1. 


\title{
An unformed chip thickness approach to study the influence of
}

\section{process vibration on machining performance in milling}

\author{
Miaoxian Guo ${ }^{1}$, Jianming Wang ${ }^{1}$, Weicheng Guo ${ }^{1}$, Jin Liu ${ }^{1}$, Xiaohui Jiang ${ }^{1}$ \\ (1. College of Mechanical Engineering, University of Shanghai for Science and \\ Technology, Shanghai 200093, China)
}

\begin{abstract}
The vibration in milling process plays a key role in machining, which will significantly affect the machining quality of workpiece. Some vibrations have negative influences on the workpiece surface, while particular vibrations are able to improve machining stability. Therefore, it is critical to distinguish the influence of different types of vibration on the machining quality. A simulation method of undeformed chip thickness considering process vibration is presented in this article, in which a finite element model is established to analyze the dynamic milling process of 7075-T651 aluminum alloy from the aspects of cutting force and temperature. A series of experiments are carried out to verify the effectiveness of the simulation model, and the results show that the proposed model is accurate in predicting milling force and temperature. Furthermore, the effect of milling vibration on machining performance is studied with the proposed method, in which the relationship between amplitude-frequency characteristics of vibration and milling forcetemperature fluctuation is revealed. The results show that the proposed method can define the influence of milling vibration and provide a basis for distinguishing favorable and unfavorable vibration parameters of machining quality in milling.
\end{abstract}

Keywords: Amplitude-frequency characteristics; Milling Vibration; Unformed chip thickness; milling force; milling temperature;

\section{Introduction}

Precision milling processes have been widely applied in manufacturing parts including automotive, aerospace, and precision machinery. In order to improve the machining quality of the parts, finite element method, numerical analysis method and experimental method were applied to predict and evaluate the machining quality [1-3]. Process vibration has an important effect on the machining quality, it is very important to distinguish favorable and unfavorable vibration parameters.

In the grinding and milling processing technology, vibration generated in the processing process has a great impact on the machining accuracy and quality [4-7]. Vibration phenomenon in the processing process will lead to poor surface quality and affect the machine life. Shtehin et al. [8] have carried out experimental research on low frequency vibration when the spherical milling cutter is machining bevels. The results show that the effect of low frequency vibration on the processing surface is more significant than that of ordinary vibration. Kecik et al. [9] studied the problem of vibration during high-speed milling, considering regenerative vibration and frictional vibration. Liu et al. [10] introduce a time-change reliability analysis method to predict the stability

*Dr. Weicheng Guo

University of Shanghai for Science \& Technology, Shanghai 200093 China.

Tel: +86 18019181533, E-mail: wcguo@usst.edu.cn 
and vibration reliability in milling process. These researches are based on the process reliability study, the vibration effect on the process performance need further study.

In contrast, vibration in the process can also have a favorable effect on the machining quality. In the area, ultrasonic assisted vibration processing plays a crucial role in improving the processing quality of parts [11-12]. The influence of vibration parameters on milling force and heat is very important in vibration-assisted milling. Verma et al. [13] evaluated the effect of process parameters on milling force experimentally, the results show that the most effective parameter of milling force is the feed, and axial vibration assistance also reduces the average milling force. Elhami et al. [14] studied the effect of mixed machining parameters on average milling force, and the results showed that the milling force of ultrasonic auxiliary milling could be reduced by about $27 \%$ compared to conventional milling. Kong et al. [15] use finite element simulation technology to find that elliptical vibration milling has a lower milling force on 1045 steel than conventional milling. Chen et al. [16] studied the milling mechanism of magnesium alloy vibration-assisted micro-milling through finite element simulation and experiments and found that vibration frequency has a significant effect on machining mechanism, such as reducing milling force and tool wear. Tao et al. [17] have established an ultrasonic vibration-assisted milling mechanism model to calculate tangential, radial and axial milling forces. The results show that when ultrasonic vibration is applied in the feed direction, the milling force is reduced.

In addition, ultrasonic assisted vibration can not only reduce the milling force, but also play an important role in reducing the milling heat. Feng et al. [18] proposed a model to analyze the ultrasonic vibration-assisted milling temperature, and the effect of milling parameters and vibration parameters on temperature is studied. Lu et al. [19] used finite element analysis techniques to study the effect of frequency and amplitude on milling temperature. The study found that the milling temperature increased with the increase of amplitude and decreased with the increase of frequency. Luo et al. [20] simulated and tested the of ultrasonic vibration-assisted milling of aluminum alloy 7075-T651, found that the milling temperature decreased accordingly with the increase of amplitude and frequency. Verma et al. [21] developed a process physics-based equation to predict temperature rise in vibration-assisted milling.

Researchers generally studied conventional milling process or ultrasonic vibration assisted milling process respectively. Most of the above studies focus on the specific frequency or amplitude range, it is important to comprehensive research on vibration parameters (wide vibration frequency range and multiple amplitude characteristics). The model with specific requirements needs to be developed to study the influence of process vibration on machining performance in milling.

In this paper, the effects of vibration frequency and amplitude on milling performance are systematically studied. Firstly, a simulation method of undeformed chip thickness considering process vibration is presented in this article, in which a finite element model is established. Taking 7075-T651 aluminum alloy as the object, the dynamic milling performance of cutting force, temperature and surface roughness is analyzed, and the accuracy of the model in predicting milling force and milling temperature was verified by experiments. Finally, the effect of milling vibration on machining performance is studied with the proposed method, and the relationship between amplitude-frequency characteristics of vibration and milling force-temperature fluctuation is revealed, which provide a basis for distinguishing favorable and unfavorable vibration parameters of machining quality. 


\section{Modelling of milling process considering vibration}

\subsection{Tool path in vibration condition}

As shown in Figure 1, the vibration in process has significant effect on trajectory of tool. In milling, the workpiece feeds to the tool at a constant milling speed, while the tool makes periodic reciprocating movements the feed direction and vertical feed direction. In Figure 1(a), when the milling tool vibrates in the vertical feed direction, the milling tool begins to move at point A, which is the midpoint of the previous cycle, and the tool moves to the vertex position of the next cycle when it moves to point $\mathrm{B}$. The vibration trajectory of the milling tool relative to the workpiece can be described as follows:

$$
\left\{\begin{array}{c}
X=v t \\
y=\operatorname{asin}\left(2 \pi f_{y} t+\varphi_{y}\right)
\end{array}\right.
$$

The speed of the tool relative to the workpiece can be expressed in the time derivative of the tool position, as follows:

$$
\left\{\begin{array}{c}
V_{x}=v \\
V_{y}=2 \pi f_{y} a \cos \left(2 \pi f_{y} t+\varphi_{y}\right)
\end{array}\right.
$$

In Figure 1(b), When the milling tool vibrates in the feed direction, the milling tool starts to move at point $\mathrm{C}$ and reaches the end of a cycle at point $\mathrm{D}$. The vibration trajectory of the milling tool relative to the workpiece is as follows:

$$
\left\{\begin{array}{c}
X=b \sin \left(2 \pi f_{x} t+\varphi_{x}\right)-v t \\
y=0
\end{array}\right.
$$

Where $\mathrm{a}$ and $\mathrm{b}$ are the amplitudes, $\mathrm{fx}$ and fy are the vibration frequencies in $\mathrm{x}$ and $\mathrm{y}$ direction, $\mathrm{t}$ is the time parameter, $\varphi \mathrm{x}$ and $\varphi \mathrm{y}$ are the initial angles, $\mathrm{v}$ is the feed rate. The speed of the tool relative to the workpiece can be expressed in the time derivative as follows:

$$
\left\{\begin{array}{c}
V_{x}=2 \pi f_{x} b \cos \left(2 \pi f_{x} t+\varphi_{x}\right)-v \\
V_{y}=0
\end{array}\right.
$$

When the tool vibrates in the feed direction and assuming that the variable $\mathrm{k}$ is the ratio of the maximum vibration speed of the tool to the milling speed $\mathrm{v}$. And $\mathrm{k}$ is expressed as:

$$
k=\frac{v}{2 \pi f_{x} b}
$$

When $\mathrm{k}<1$, the tool is separated from the chips and workpieces. Tool and chip separation can effectively reduce milling temperature and milling force.
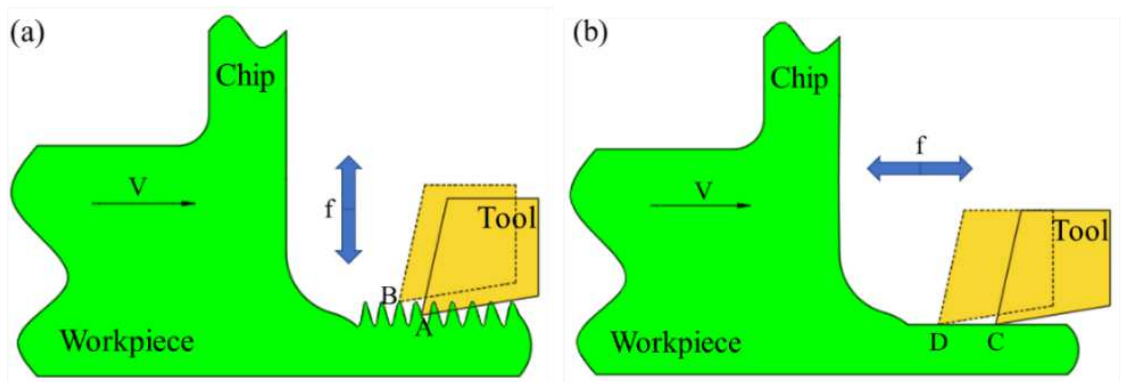

Figure 1 Tool path in vibration condition: (a) Vibration in vertical feed direction, (b) Vibration in feed direction 


\subsection{Unformed chip thickness considering vibration}

Based on the characteristics of slot milling, a semicircular model was established by considering the machining paths of two adjacent cutter teeth along the feed direction, as shown in Figure 2.

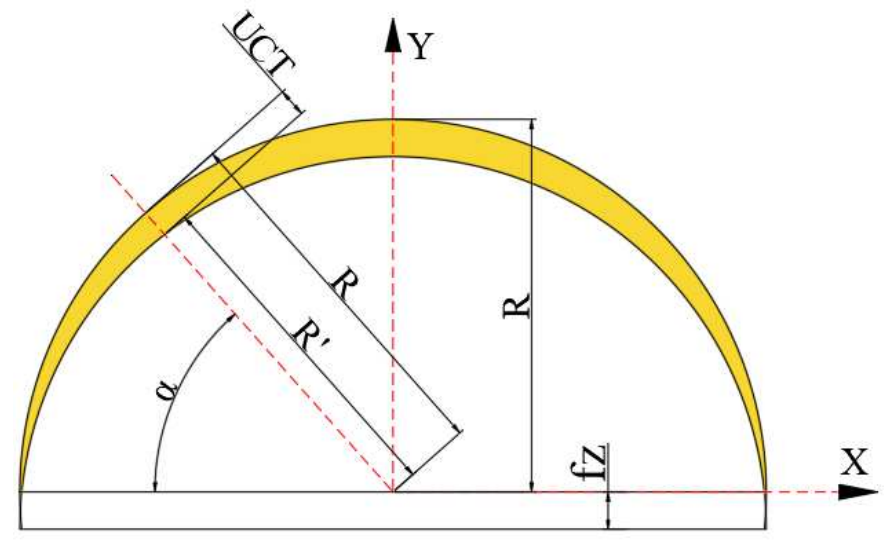

Figure 2 Unformed chip thickness model

$$
R^{\prime 2}+f_{z}^{2}-2 \cdot f_{z} \cdot R^{\prime} \cdot \cos \left(\alpha+90^{\circ}\right)-R^{2}=0
$$

(6)

$$
U C T=R-R^{\prime}
$$

Where $\mathrm{fz}$ is the tool feed per tooth, $\mathrm{R}$ is the tool radius, $\alpha$ is the milling arc angle, UCT is the thickness of unformed chips [22]. It can be seen from the milling model and formula, the parameters affecting the thickness of unformed chips are tool diameter and feed per toot. Furthermore, the vibration in process would also impact on the unformed chip thickness. Figure 3 shows the variation of the thickness of the undeformed chip with the Angle of the arc zone without vibration and with vibration taken into account. The tool diameter is $8 \mathrm{~mm}$, the feed speed is $0.15 \mathrm{~mm} / \mathrm{z}$, the amplitude is $20 \mu \mathrm{m}$, and the frequency is $5000 \mathrm{~Hz}$. The above undeformed chip thickness theory was applied to AdvantEdge software, and a milling model was established, as shown in Figure 4.

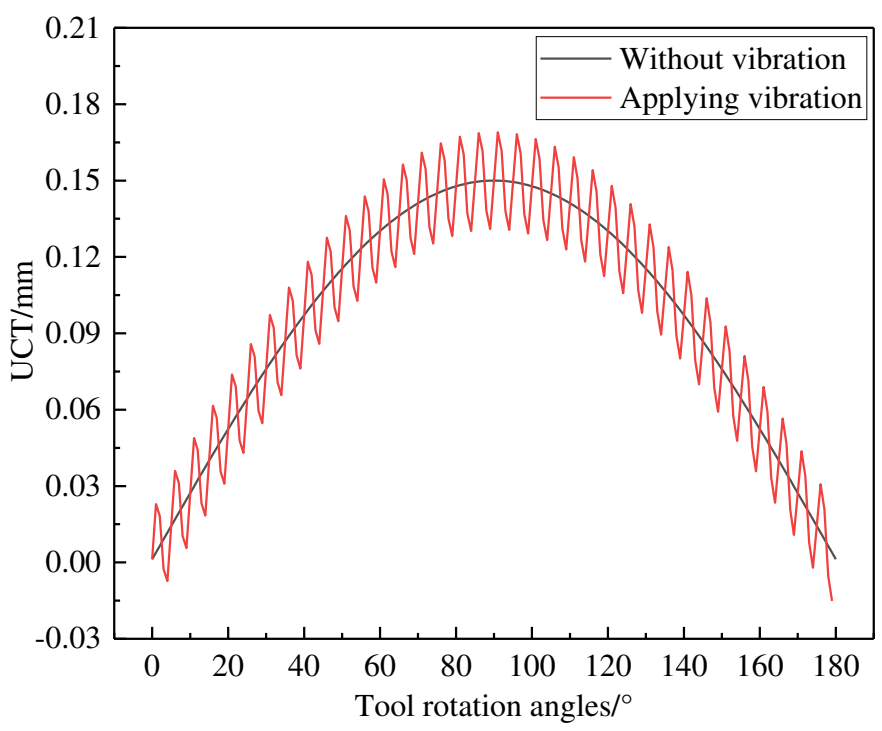

Figure 3 Unformed chip thickness for normal and vibration milling 


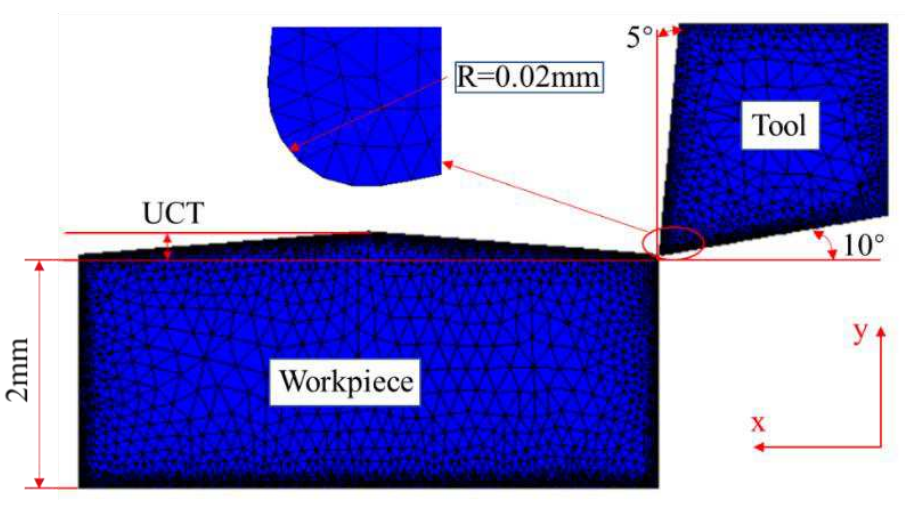

Figure 4 Milling simulation model

\section{Finite element analysis and its verification}

\subsection{Simulation parameters}

The aluminum alloy 7075-T651 has good fatigue resistance, its chemical composition is shown in Table 1[20]. Carbide tools have the advantages of high hardness, good temperature hardness and good wear resistance, the parameters of tool are recorded in Table 2. The material characteristic parameters of the workpiece and tool are recorded in Table 3.

Table 1 Chemical composition of aluminum alloy 7075-T651 (wt\%)

\begin{tabular}{ccccccccc}
\hline $\mathrm{Al}$ & $\mathrm{Zn}$ & $\mathrm{Mg}$ & $\mathrm{Cu}$ & $\mathrm{Fe}$ & $\mathrm{Si}$ & $\mathrm{Mn}$ & $\mathrm{Ti}$ & $\mathrm{Cr}$ \\
\hline $87.1 \sim 91.4$ & $5.1 \sim 6.1$ & $2.1 \sim 2.9$ & $1.2 \sim 2$ & 0.5 & 0.4 & 0.3 & 0.2 & $0.18 \sim 0.28$ \\
\hline
\end{tabular}

Table 2 Tool parameters

\begin{tabular}{ccccccc}
\hline $\begin{array}{c}\text { Tool } \\
\text { diameter(mm) }\end{array}$ & Material & $\begin{array}{c}\text { Rake } \\
\text { angle }\left({ }^{\circ}\right)\end{array}$ & $\begin{array}{c}\text { Clearance } \\
\text { angle }\left({ }^{\circ}\right)\end{array}$ & $\begin{array}{c}\text { Tool helix } \\
\text { angle }\left({ }^{\circ}\right)\end{array}$ & Tool flutes & $\begin{array}{c}\text { Milling } \\
\text { edge } \\
\text { radius(mm) }\end{array}$ \\
\hline 8 & $\begin{array}{c}\text { Carbide- } \\
\text { grade }\end{array}$ & 5 & 10 & 30 & 3 & 0.02 \\
\hline
\end{tabular}

Table 3 Material characteristic parameters of Aluminum alloy 7075-T651 and Carbide tool

\begin{tabular}{ccc}
\hline Material parameters & Al7075-T651 & Carbide tool \\
\hline Density $/\left(\mathrm{kg}^{-3} \mathrm{~m}^{-3}\right)$ & 2810 & 15700 \\
Elastic modulus $(\mathrm{Gpa})$ & 71.7 & 705 \\
Poisson's ratio & 0.33 & 0.23 \\
Specific heat $\left(\mathrm{J} \cdot \mathrm{kg}^{-1} \cdot \mathrm{K}^{-1}\right)$ & 1075 & 178 \\
conductivity $/\left(\mathrm{W} \cdot \mathrm{m}^{1} \cdot \mathrm{K}\right)$ & 151.6 & 24 \\
The coefficient of & 25.2 & 5 \\
expansion $/ 10 \cdot \mathrm{e}^{-6}$ & & \\
melting point $/ \mathrm{K}$ & 908 & \\
\hline
\end{tabular}

The Johnson-Cook model (JC model) is a good reflection of the high temperature deformation of metals at high strain, high strain rate and high temperature [23]. For finite element simulation of material deformation processes, such as machining and plastic forming, the control equations are:

$$
\sigma=\left(A+B \varepsilon^{n}\right)\left(1+C \ln \frac{\dot{\varepsilon}}{\dot{\varepsilon}_{0}}\right)\left[1-\left(\frac{T-T_{r}}{T_{m}-T_{r}}\right)^{m}\right]
$$


Where $\sigma$ is the flow stress; $\varepsilon$ is the effective plastic strain; $\dot{\varepsilon}$ is the effective plastic strain rate; $\dot{\varepsilon}_{0}$ is the reference plastic strain rate; $\mathrm{T}$ is the ambient temperature; $T_{m}$ is the melting point temperature of the material; A is the yield stress of the material; $\mathrm{B}$ is the processing hardening parameter of the material; $\mathrm{C}$ is the strain rate reinforcement index; $\mathrm{m}$ is the temperature change rate index; $\mathrm{n}$ is the strain hardening index. The $\mathrm{J}$-C model parameters for 7075-T651 aluminum alloys are shown in Table 4[24].

Table 4 J-C model parameters for 7075-T651 aluminum alloys

\begin{tabular}{cccccccc}
\hline$A(M P a)$ & $B(M P a)$ & $C$ & $m$ & $n$ & $\dot{\varepsilon}_{0}\left(s^{-1}\right)$ & $T_{r}(K)$ & $T_{m}(K)$ \\
\hline 527 & 575 & 0.017 & 1.61 & 0.72 & 1 & 298 & 908 \\
\hline
\end{tabular}

In the finite element model of the milling process, the critical value reached by plastic strain accumulation is often used as a criterion for chip damage, and the Johnson-Cook fracture criterion is used as the failure criterion in this study. The failure criterion provides a calculation method for the equivalent plastic strain when the material reaches the failure point, and the fracture failure parameter $\mathrm{D}$ is applied to determine the removal of the material:

$$
D=\sum \frac{\Delta \varepsilon}{\varepsilon^{f}}
$$

Where $\varepsilon^{f}$ is a failure strain; $\Delta \varepsilon$ indicates an increase in effective plastic strain at a unit load. According to the Johnson-Cook fault guidelines, the fault failure strain of the material is calculated as follows [25]:

$$
\varepsilon^{f}=\left[d_{1}+d_{2} \exp \left(d_{3} \frac{\delta_{m}}{\bar{\delta}}\right)\right]\left(1+d_{4} \ln \frac{\dot{\varepsilon}}{\dot{\varepsilon}_{0}}\right)\left[1+d_{5}\left(\frac{T-T_{r}}{T_{m}-T_{r}}\right)\right]
$$

In which $\delta_{m}$ represents the mean of positive pressure; $\bar{\delta}$ is effective; $d_{1}-d_{5}$ is the material failure parameter, the J-C damage model parameters for the 7075-T651 aluminum alloy are shown in Table 5[24].

Table 5 J-C damage model parameters for 7075-T651 aluminum alloys

\begin{tabular}{ccccc}
\hline$d_{1}$ & $d_{2}$ & $d_{3}$ & $d_{4}$ & $d_{5}$ \\
\hline 0.11 & 0.572 & -3.446 & 0.016 & 1.099 \\
\hline
\end{tabular}

The software usually sets the relationship between the tool workpiece (rigid elastic-plastic) to ensure that the simulation process of the tool mesh does not distort the iteration. The friction factor between the tool and the workpiece (set this to 0.5 for this article) plays a decisive role in the final simulation results, and the software in this paper uses the friction relation as coulomb formula. As shown in the following formula:

$$
F_{f} \leq \mu \cdot F
$$

Where $\mathrm{F}$ is the force between the tool and the workpiece surface, $\mu$ is the friction factor, $F_{\mathrm{f}}$ is the friction force caused by friction.

The main simulation parameters were shown in Table 6 .

Table 6 Main simulation parameters

\begin{tabular}{cccccc}
\hline & $\begin{array}{c}\text { Spindle } \\
\text { speed(r/min })\end{array}$ & $\begin{array}{c}\text { Milling depth } \\
(\mathrm{mm})\end{array}$ & $\begin{array}{c}\text { Feed } \\
\text { speed }(\mathrm{m} / \mathrm{min})\end{array}$ & $\begin{array}{c}\text { Frequency } \\
(\mathrm{kHz})\end{array}$ & $\begin{array}{c}\text { Amplitude } \\
(\mu \mathrm{m})\end{array}$ \\
\hline (I) & 4000 & 0.6 & 0.8 & 0 & 0 \\
(II) & 4000 & 0.6 & 0.8 & 20 & 10 \\
\hline
\end{tabular}




\subsection{Simulation results and analysis}

As shown in Figure 5, the simulation result of milling force in non-vibration and vibration condition is present. It can be found that the milling forces both obviously showed parabolic trend, which is in line with the change law of unformed chip thickness in slot milling. Furthermore, while in milling without vibration, the milling force has only a small range of fluctuations, which is the inherent characteristics of milling; in milling with vibration, the milling force will produce periodic large-scale fluctuations with vibration, which is mainly due to the periodic movement of the tool. To obtain the force values, the force data is post-processing as shown in Figure $5 \mathrm{c}$, in which the band-pass filtering is applied to calculate the periodic fluctuation curve, and the force fluctuations after filtering is consistent with the applied vibration signal. The average milling force is obvious in the figures, and the milling force fluctuation is the value of function amplitude. The average milling force directly affects the machining quality, while the fluctuation value of milling force affects the stability of the machining system.

(a)

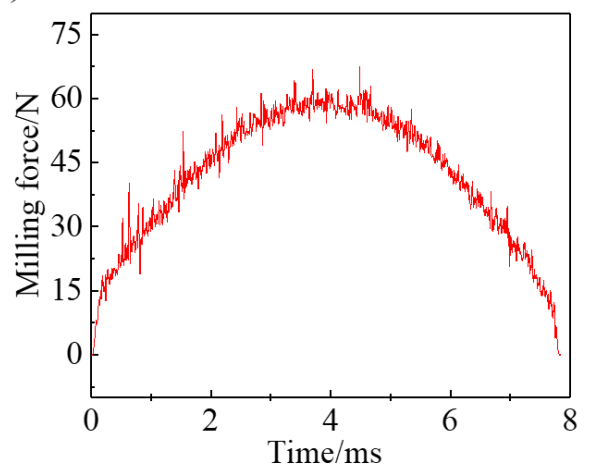

(b)

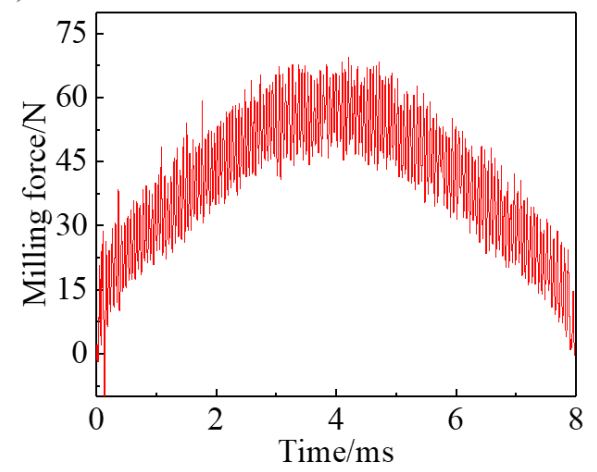

(c)

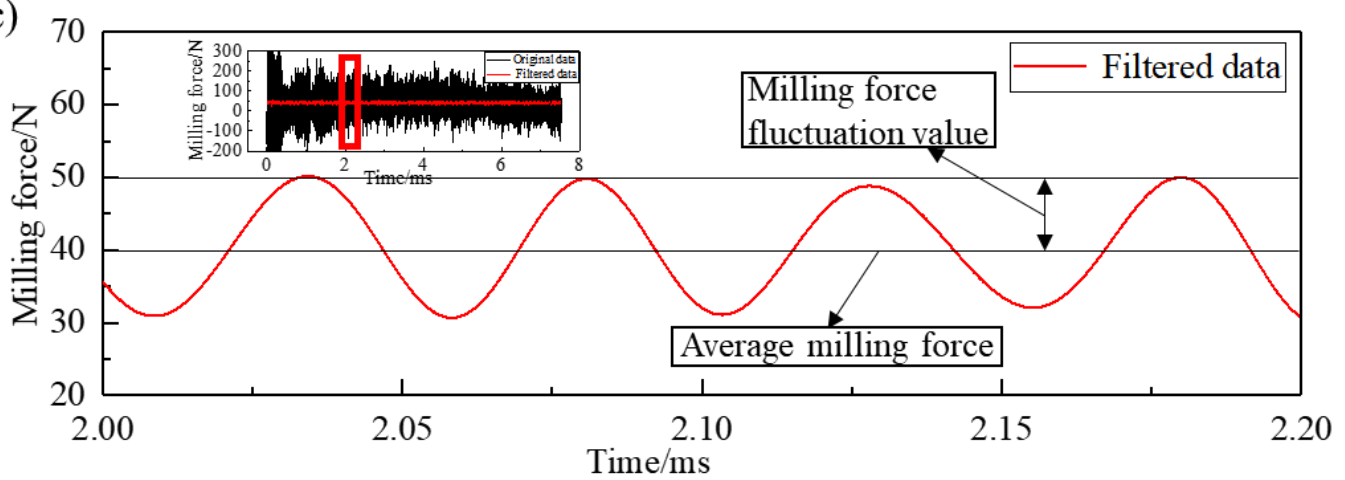

Figure 5 Milling force simulation results:(a) Milling without vibration (Parameter I), (b) Milling with vibration (Parameter II), (c) Average and fluctuation value of milling force (Parameter II)

As shown in Figure 6, the results of the milling temperature simulation in non-vibration and vibration condition is present respectively. It can be found that the highest temperature in the milling area is at the tip of the tool, and the maximum temperature of milling with vibration is higher than that of without milling. Furthermore, from the partial amplification of the machining workpiece surface, it can be found that the non-vibration machined surface is relatively flat, while vibration machined surface appear undulating wave, which matches with the movement between the tool and the workpiece. In milling process, the milling temperature is mainly concentrated in the first and second milling areas, in the first milling area, the temperature is mainly caused by the plastic deformation of metal materials; in the second milling area, the temperature mainly 
generated by the friction of the rear face. A gradient from high to low temperature is formed inside the workpiece, which has an important effect on the surface temperature of the processed workpiece.
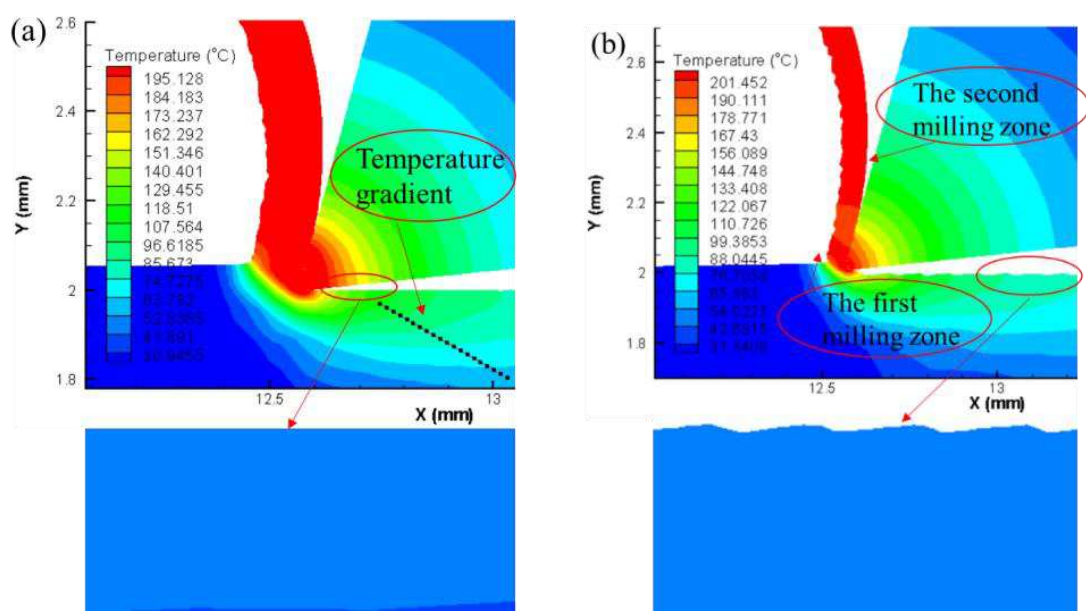

Figure 6 Milling Temperature Simulation Results:(a) Milling without vibration (Parameter I), (b) Milling with vibration (Parameter II)

\subsection{Experimental setup}

This verification experiment was carried out on the carved Carver S600A vertical milling machine as shown in Figure 7. With special designed workpieces fixed on the piezoelectric ceramic driver platform (model specification PT1500707301), the piezoelectric ceramic driver are fixed on the dynamometer to produce certain vibration frequency and amplitude. The milling temperature is measured by the K-type thermocouple using NI 9213 acquisition card, the milling forces are measured by a Kistler Force Dynamometer (Type 9139AA) mounted at the machine bed, which the sampling rate is set to $2500 \mathrm{~Hz}$. In the test, the workpieces material and tool are chosen as in table 1 and table 2, which are same as that in simulation.

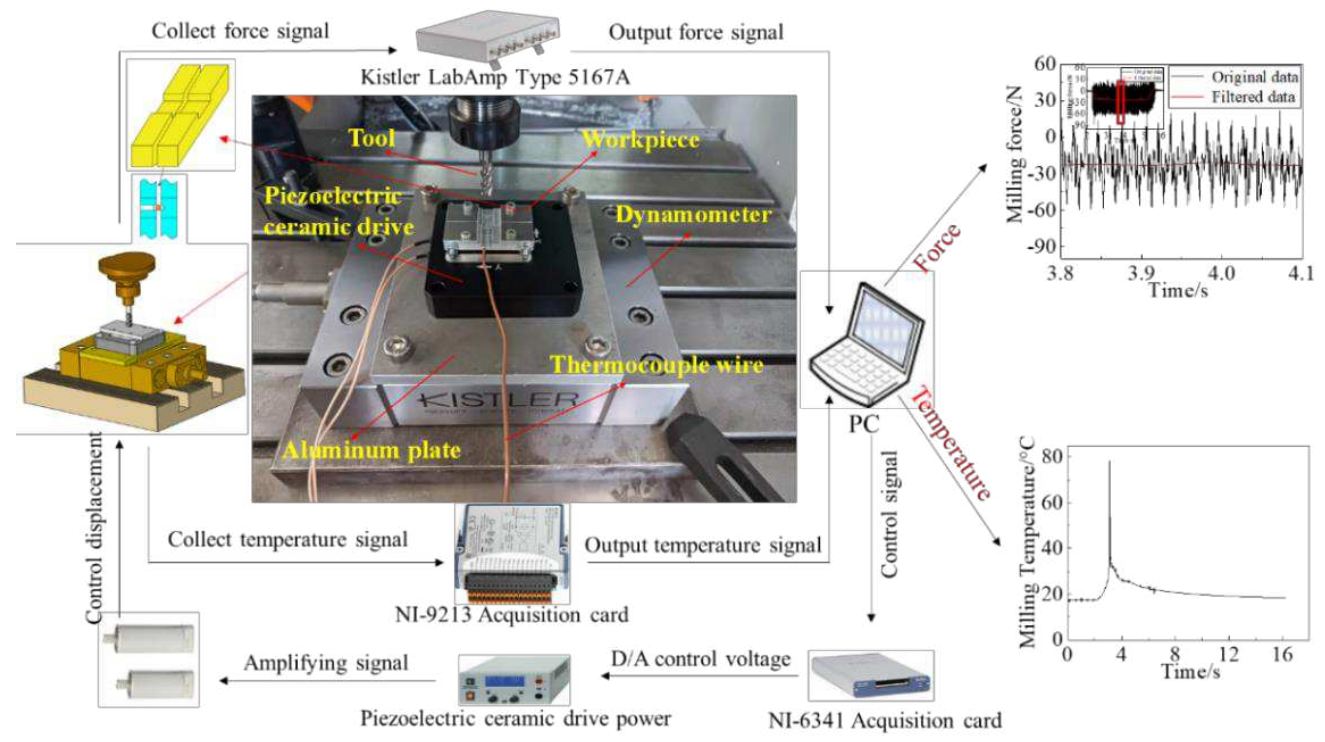

Figure 7 Verification test setup 


\subsection{Experimental verification results}

The Measurement results of milling forces and milling temperatures are shown in Figure 7. The milling parameters are as follows: spindle speed $4000 \mathrm{r} / \mathrm{min}$, milling depth $0.6 \mathrm{~mm}$, feed speed $0.8 \mathrm{~m} / \mathrm{min}$. The vibration parameters are as follows: amplitude $10 \mu \mathrm{m}$, frequency $2 \mathrm{kHz}$. The finite element simulation model is experimentally verified from the milling force and milling temperature, and the results are shown in Figure 8. It can be found that the maximum error of force between the experimental and simulation is $12 \%$, while the maximum error of temperature is 15.7\%. The simulation results had good agreement with the experiment observations, which proves the accuracy of the simulation model, and can realize the simulation prediction of the milling force and temperature.

(a)

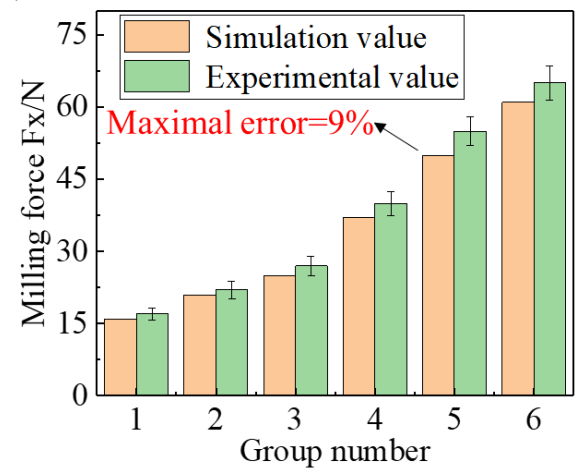

(b)

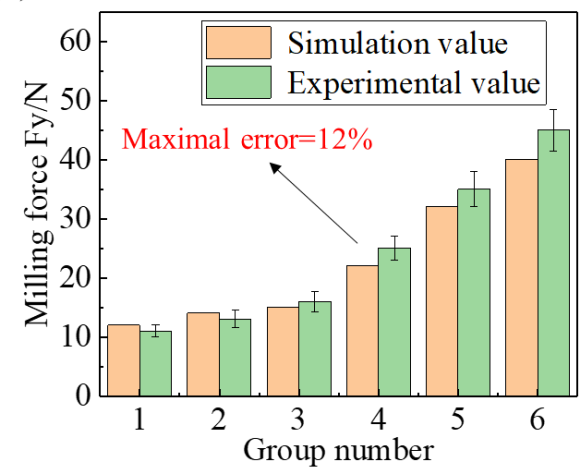

(c)

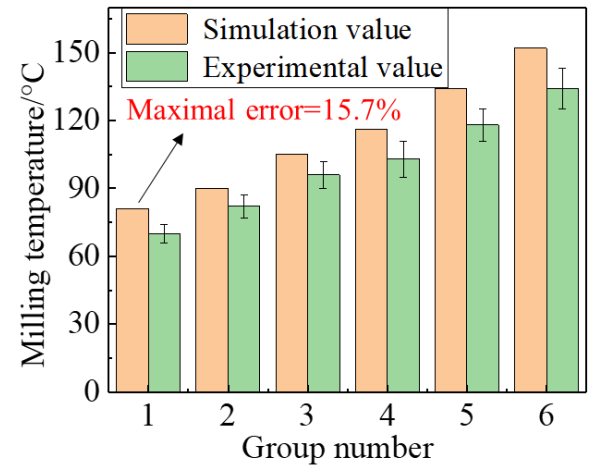

Figure 8 Verification results of milling force and milling temperature:(a) Milling force Fx,(b) Milling force Fy,(c) Milling temperature

\section{Effect of Vibration characterization parameters on machining performance}

In milling of 7075-T651 aluminum alloys, the vibration characterization parameters (amplitude, frequency) have impact on milling force and temperature, it cannot be ignored in precision manufacturing process. It is very difficult to obtain different vibration characterization parameters in experiments, the simulation method is applied to analyze the effect of vibration characterization parameters on processing results. 


\subsection{Effect of vibration frequency on milling force and temperature}

The single factor test of frequency was conducted in simulation as in Table 7, vibration of amplitude of $10 \mu \mathrm{m}$ was applied to the feed direction and vertical feed direction respectively. The simulation results are shown in Table 7, the relationship between vibration frequency and milling force and milling temperature is analyzed as shown in Figure 9. As in Figure 9a and Figure 9b, while the vibration frequency in the feed direction increases, the average milling force in the $\mathrm{x}$ and y directions varies little when the frequency is below $20 \mathrm{kHz}$, and decreases gradually when the frequency is greater than $20 \mathrm{kHz}$. The average surface temperature of the workpiece increases and then gradually decrease with the frequency. Furthermore, the milling force fluctuation value of vibration in the $\mathrm{x}$ directions gradually increased when the frequency is more than $20 \mathrm{kHz}$.

As in Figure 9c and Figure 9d, while the vibration frequency in the vertical feed direction increases, the average milling force of vibration in the $\mathrm{x}$ and $\mathrm{y}$ directions varies when the frequency is lower than $20 \mathrm{kHz}$, and decreases gradually when the frequency is greater than $20 \mathrm{kHz}$ The average surface temperature of the workpiece increases and then gradually decrease with the frequency. Furthermore, the milling force fluctuation value of vibration in the y directions gradually increased when the frequency is more than $20 \mathrm{kHz}$.

Table 7 Effect of different vibration frequencies on processing results

\begin{tabular}{|c|c|c|c|c|c|c|c|c|c|}
\hline NO. & $\begin{array}{l}\text { Spindle } \\
\text { speed } \\
(\mathrm{r} / \mathrm{min})\end{array}$ & $\begin{array}{l}\text { Feed } \\
\text { rate } \\
(\mathrm{mm} / \mathrm{t})\end{array}$ & $\begin{array}{l}\text { Milling } \\
\text { depth } \\
(\mathrm{mm})\end{array}$ & $\begin{array}{c}\text { Frequency } \\
(\mathrm{Hz})\end{array}$ & $\begin{array}{l}\text { Average } \\
\text { value of } \mathrm{Fx} \\
\text { (N) }\end{array}$ & $\begin{array}{l}\text { Average } \\
\text { value of } \\
\text { Fy }(\mathrm{N})\end{array}$ & $\begin{array}{c}\text { Average } \\
\text { temperature of } \\
\text { the processed } \\
\text { surface }\left({ }^{\circ} \mathrm{C}\right)\end{array}$ & $\begin{array}{l}\text { Fluctuation } \\
\text { value of } \\
\operatorname{Fx}(N)\end{array}$ & $\begin{array}{l}\text { Fluctuation } \\
\text { value of } \\
\text { Fy(N) }\end{array}$ \\
\hline
\end{tabular}

\begin{tabular}{|c|c|c|c|c|c|c|c|c|c|c|c|c|c|c|}
\hline & & & & & \\
\hline & & & & & $F$ & $\mathrm{~V}$ & $\mathrm{~F}$ & $\mathrm{~V}$ & $\bar{F}$ & $\mathrm{~V}$ & $\bar{F}$ & $\mathrm{~V}$ & $\mathrm{~F}$ & $\mathrm{~V}$ \\
\hline 1 & 10000 & 0.1 & 0.2 & 1000 & 19.5 & 19.2 & 9.2 & 8.8 & 182.2 & 165.7 & 3.5 & 9.1 & 1.3 & 2.4 \\
\hline 2 & 10000 & 0.1 & 0.2 & 2000 & 19.3 & 19.7 & 9.1 & 8.9 & 183.8 & 172.4 & 2.5 & 5.3 & 1.1 & 1.5 \\
\hline 3 & 10000 & 0.1 & 0.2 & 3000 & 19.9 & 19.2 & 9.2 & 8.7 & 185.6 & 178.6 & 2.0 & 3.6 & 0.9 & 1.7 \\
\hline 4 & 10000 & 0.1 & 0.2 & 4000 & 19.5 & 19.3 & 9.3 & 8.6 & 188.1 & 188.2 & 1.2 & 3.7 & 0.6 & 1.6 \\
\hline 5 & 10000 & 0.1 & 0.2 & 5000 & 20.1 & 19.4 & 9.1 & 9.0 & 190.3 & 188.5 & 1.0 & 2.5 & 0.5 & 2.0 \\
\hline 6 & 10000 & 0.1 & 0.2 & 6000 & 19.8 & 19.6 & 9.2 & 8.8 & 187.7 & 191.3 & 0.6 & 2.4 & 0.4 & 1.1 \\
\hline 7 & 10000 & 0.1 & 0.2 & 7000 & 19.8 & 19.7 & 9.1 & 8.9 & 186.7 & 190.2 & 1.1 & 1.3 & 0.5 & 0.8 \\
\hline 8 & 10000 & 0.1 & 0.2 & 8000 & 20.2 & 19.3 & 9.1 & 9.5 & 186.8 & 188.7 & 0.5 & 2.8 & 0.3 & 4.2 \\
\hline 9 & 10000 & 0.1 & 0.2 & 9000 & 19.5 & 19.9 & 9.0 & 9.4 & 184.4 & 192.6 & 0.7 & 1.2 & 0.2 & 2.0 \\
\hline 10 & 10000 & 0.1 & 0.2 & 10000 & 19.1 & 19.5 & 9.0 & 9.8 & 183.2 & 189.7 & 2.2 & 3.2 & 1.0 & 5.3 \\
\hline 11 & 10000 & 0.1 & 0.2 & 20000 & 19.0 & 20.4 & 8.7 & 12.0 & 182.9 & 188.1 & 5.1 & 4.6 & 1.4 & 7.5 \\
\hline 12 & 10000 & 0.1 & 0.2 & 30000 & 19.1 & 19.0 & 8.8 & 12.0 & 180.1 & 182.3 & 10.2 & 4.0 & 1.8 & 11.4 \\
\hline 13 & 10000 & 0.1 & 0.2 & 40000 & 18.4 & 19.5 & 8.6 & 11.7 & 178.0 & 185.5 & 13.3 & 3.1 & 2.0 & 18.3 \\
\hline 14 & 10000 & 0.1 & 0.2 & 50000 & 18.0 & 18.7 & 8.5 & 11.0 & 177.5 & 180.3 & 17.5 & 3.5 & 2.5 & 20.6 \\
\hline 15 & 10000 & 0.1 & 0.2 & 60000 & 17.5 & 18.3 & 8.2 & 10.3 & 176.7 & 178.4 & 22.1 & 2.5 & 2.2 & 35.4 \\
\hline 16 & 10000 & 0.1 & 0.2 & 70000 & 17.3 & 17.8 & 8.2 & 10.2 & 175.7 & 168.7 & 24.0 & 2.8 & 2.1 & 40.2 \\
\hline 17 & 10000 & 0.1 & 0.2 & 80000 & 17.2 & 17.3 & 8.1 & 9.7 & 172.5 & 160.5 & 28.3 & 3.0 & 2.2 & 45.8 \\
\hline 18 & 10000 & 0.1 & 0.2 & 90000 & 15.7 & 16.5 & 7.6 & 9.3 & 170.5 & 155.7 & 30.1 & 3.5 & 3.2 & 48.5 \\
\hline 19 & 10000 & 0.1 & 0.2 & 100000 & 15.3 & 16.0 & 7.0 & 8.5 & 169.6 & 150.4 & 35.2 & 4.2 & 4.1 & 50.2 \\
\hline
\end{tabular}

F --- Applying Feed direction vibration; v--- Applying Vertical feed direction vibration 
(a)

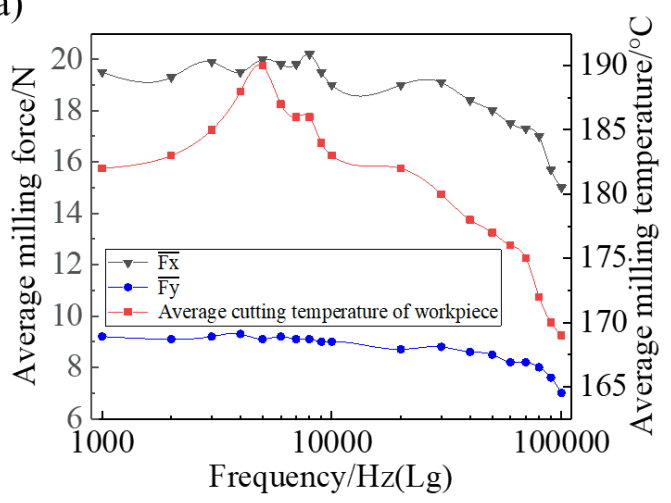

(c)

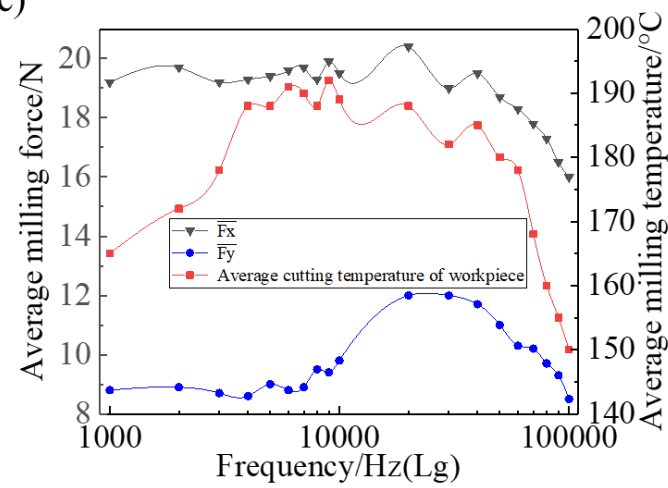

(b)

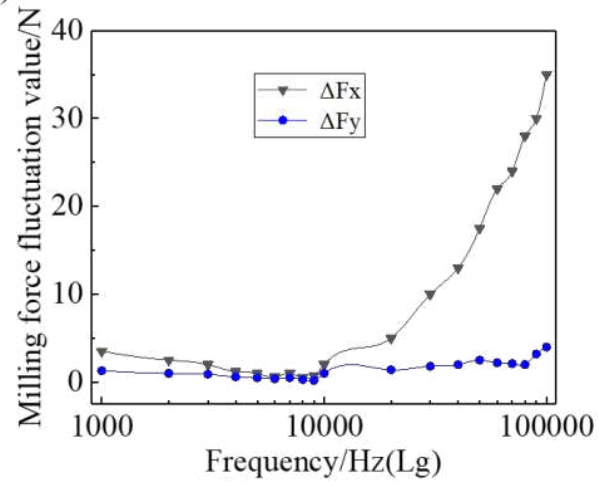

(d)

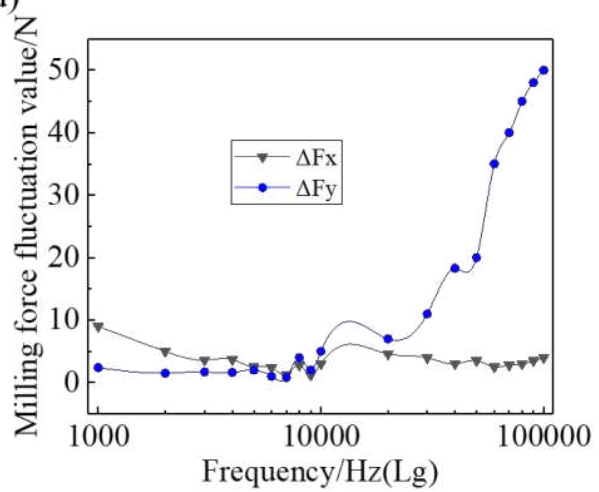

Figure 9 Effect of vibration frequency on the average milling force, temperature and milling force fluctuation values:(a) Average milling force and temperature applying feed direction vibration, (b) Milling force fluctuation value applying feed direction vibration, (c) Average milling force and temperature applying vertical feed direction vibration, (d) Milling force fluctuation value applying vertical feed direction vibration

\subsection{Effect of amplitude on milling force and temperature}

\subsubsection{Effect of amplitude on milling force and temperature at low frequency vibration}

The single factor test of amplitude was conducted in simulation as processing parameters in Table 8 , and vibration frequency of $2 \mathrm{kHz}$ was applied to the feed direction and vertical feed direction. The simulation results are shown in Table 8, the relationship between amplitude and milling force and milling temperature is analyzed as shown in Figure 10. As in Figure 10a and Figure 10b, with the increase of the amplitude in the feed direction, the average milling forces of vibration in $\mathrm{x}$ and $\mathrm{y}$ directions remain basically unchanged, while the average temperature of the surface of the workpiece decreases gradually. As shown in Figure 10c and Figure 10d, With the increase of the amplitude in the vertical feed direction, the average milling force of vibration in $\mathrm{x}$ and $y$ directions and the average surface temperature of the workpiece show an increasing trend, the milling force fluctuation value of vibration in the $\mathrm{x}$ and $\mathrm{y}$ directions are gradually increasing.

In summary, in the situation of low frequency vibration in vertical feed direction, the vibration amplitude will increase the average milling force, temperature and milling force fluctuations, resulting in poor machining quality and machining system stability.

Table 8 Effect of different amplitudes (low frequency vibration) on processing results 


\begin{tabular}{|c|c|c|c|c|c|c|c|c|c|}
\hline NO. & $\begin{array}{l}\text { Spindle } \\
\text { speed } \\
(\mathrm{r} / \mathrm{min})\end{array}$ & $\begin{array}{l}\text { Feed } \\
\text { rate } \\
(\mathrm{mm} / \mathrm{t})\end{array}$ & $\begin{array}{l}\text { Milling } \\
\text { depth } \\
(\mathrm{mm})\end{array}$ & $\begin{array}{l}\text { Amplitude } \\
\quad(\mu \mathrm{m})\end{array}$ & $\begin{array}{l}\text { Average } \\
\text { value of } F x \\
\text { (N) }\end{array}$ & $\begin{array}{l}\text { Average } \\
\text { value of } \\
\text { Fy }(\mathrm{N})\end{array}$ & $\begin{array}{c}\text { Average } \\
\text { temperature of } \\
\text { the processed } \\
\text { surface }\left({ }^{\circ} \mathrm{C}\right)\end{array}$ & $\begin{array}{c}\text { Fluctuatio } \\
\mathrm{n} \text { value of } \\
\mathrm{Fx}(\mathrm{N})\end{array}$ & $\begin{array}{c}\text { Fluctuation } \\
\text { value of } \mathrm{Fy}(\mathrm{N})\end{array}$ \\
\hline
\end{tabular}

\begin{tabular}{|c|c|c|c|c|c|c|c|c|c|c|c|c|c|c|}
\hline & & & & & $\bar{F}$ & $\mathrm{~V}$ & $\mathrm{~F}$ & $\mathrm{~V}$ & $\mathrm{~F}$ & $\mathrm{~V}$ & $\mathrm{~F}$ & $\mathrm{~V}$ & $\mathrm{~F}$ & $\bar{V}$ \\
\hline 1 & 10000 & 0.1 & 0.2 & 10 & 19.3 & 19.7 & 9.1 & 8.9 & 182.4 & 193.4 & 2.5 & 5.0 & 1.0 & 1.5 \\
\hline 2 & 10000 & 0.1 & 0.2 & 20 & 19.3 & 19.3 & 9.0 & 8.3 & 176.5 & 190.6 & 2.4 & 7.2 & 1.1 & 3.0 \\
\hline 3 & 10000 & 0.1 & 0.2 & 30 & 19.4 & 19.7 & 9.0 & 8.3 & 170.3 & 206.2 & 2.3 & 9.1 & 1.1 & 3.1 \\
\hline 4 & 10000 & 0.1 & 0.2 & 40 & 19.4 & 20.2 & 9.1 & 10.5 & 166.7 & 213.8 & 2.3 & 11.8 & 1.2 & 8.2 \\
\hline 5 & 10000 & 0.1 & 0.2 & 50 & 19.5 & 23.4 & 9.1 & 20.5 & 165.2 & 218.5 & 2.2 & 18.6 & 1.2 & 27.5 \\
\hline 6 & 10000 & 0.1 & 0.2 & 60 & 19.3 & 27.1 & 9.0 & 30.1 & 163.8 & 219.3 & 2.2 & 26.5 & 1.1 & 43.9 \\
\hline 7 & 10000 & 0.1 & 0.2 & 70 & 19.2 & 29.1 & 9.0 & 35.8 & 160.5 & 221.6 & 2.2 & 30.9 & 1.2 & 55.2 \\
\hline 8 & 10000 & 0.1 & 0.2 & 80 & 19.1 & 30.3 & 8.9 & 40.6 & 159.2 & 223.4 & 2.3 & 33.7 & 1.3 & 63.4 \\
\hline 9 & 10000 & 0.1 & 0.2 & 90 & 19.0 & 32.5 & 8.8 & 46.6 & 157.3 & 225.8 & 2.2 & 37.5 & 1.4 & 73.4 \\
\hline 10 & 10000 & 0.1 & 0.2 & 100 & 19.1 & 33.2 & 8.8 & 49.5 & 155.2 & 228.7 & 2.2 & 40.8 & 1.5 & 80.5 \\
\hline
\end{tabular}

F --- Applying Feed direction vibration; v--- Applying Vertical feed direction vibration

(a)

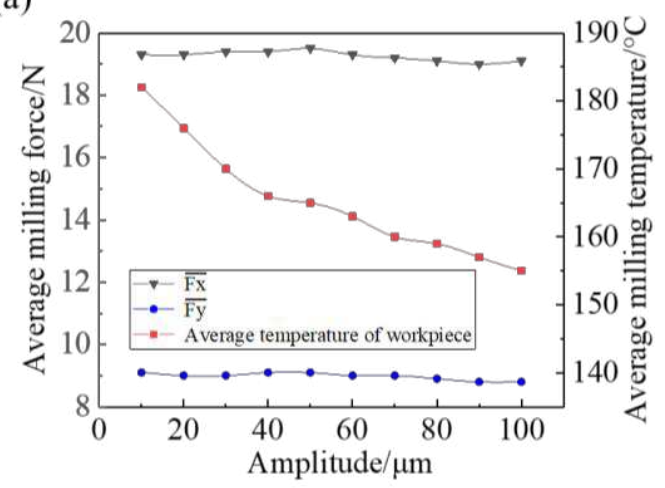

(c)

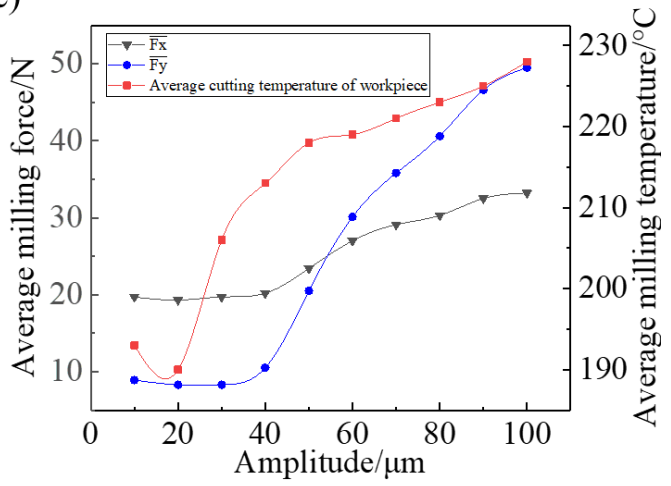

(b)

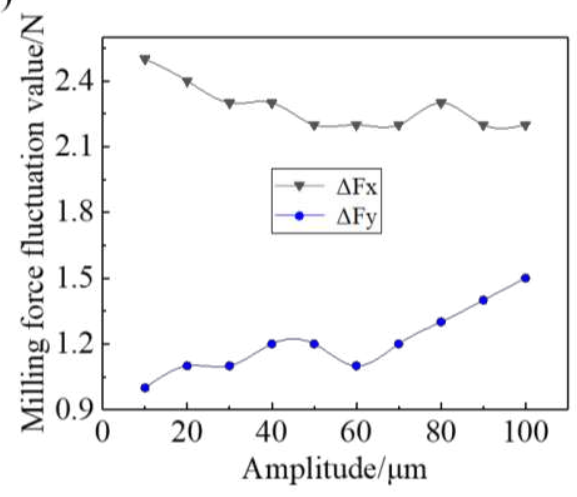

(d)

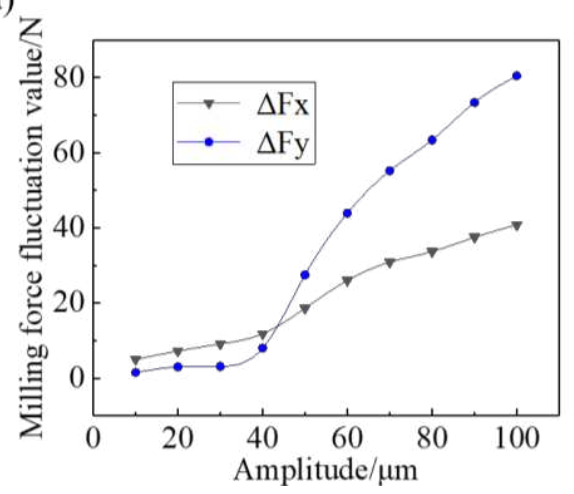

Figure 10 Effect of amplitude $(2 \mathrm{kHz})$ on average milling force, temperature, and milling force fluctuations: (a) Average milling force and temperature applying feed direction vibration,(b) Milling force fluctuation value applying feed direction vibration,(c) Average milling force and temperature applying vertical feed direction vibration,(d) Milling force fluctuation value applying vertical feed direction vibration

\subsubsection{Effect of amplitude on milling force and temperature at ultrasonic vibration}


The single factor test of amplitude was conducted in simulation as processing parameters in Table 9, and vibration frequency of $20 \mathrm{kHz}$ was applied to the feed direction and vertical feed direction. The simulation results are shown in Table 9, the relationship between amplitudes and milling force and milling temperature is analyzed as shown in Figure 11. As in Figure 11a and Figure 11b, with the increase of the amplitude in the feed direction, the average milling force of vibration in $\mathrm{x}, \mathrm{y}$ direction and the average temperature of the surface of the workpiece decreases gradually, it is because that the ultrasonic vibration causes intermittent milling of the tool, decreasing the average milling force and milling temperature. The milling force fluctuation value is gradually increasing with the amplitude increase. Therefore, the selection of amplitude is very important to the stability of the system in ultrasonic assisted milling.

As can be seen from Figure 11c and Figure 11d, with the increase of the amplitude in the vertical feed direction, the average milling force of vibration in the $\mathrm{x}$ direction decreases gradually, while the average milling force in the y direction increases gradually. The average milling temperature of workpiece surface decreases at first stage and then increases gradually. The change in temperature is due to the change in the dominance position of cutter-workpiece discontinuous milling and increased milling area. The milling force fluctuation values of vibration in $\mathrm{x}$ and $\mathrm{y}$ directions gradually increase, and the amplitude of the milling force fluctuation value in $y$ direction increases more obviously.

Table 9 Effect of different amplitudes (ultrasonic vibration) on processing results

\begin{tabular}{|c|c|c|c|c|c|c|c|c|c|}
\hline NO. & $\begin{array}{l}\text { Spindle } \\
\text { speed } \\
(\mathrm{r} / \mathrm{min})\end{array}$ & $\begin{array}{l}\text { Feed } \\
\text { rate } \\
(\mathrm{mm} / \mathrm{t})\end{array}$ & $\begin{array}{l}\text { Milling } \\
\text { depth } \\
(\mathrm{mm})\end{array}$ & $\begin{array}{l}\text { Amplitude } \\
(\mu \mathrm{m})\end{array}$ & $\begin{array}{c}\text { Average } \\
\text { value of Fx } \\
\text { (N) }\end{array}$ & $\begin{array}{c}\text { Average } \\
\text { value of } \\
\text { Fy }(N)\end{array}$ & $\begin{array}{c}\text { Average } \\
\text { temperature of } \\
\text { the processed } \\
\text { surface }\left({ }^{\circ} \mathrm{C}\right)\end{array}$ & $\begin{array}{c}\text { Fluctuation } \\
\text { value of } F x(N)\end{array}$ & $\begin{array}{l}\text { Fluctuation } \\
\text { value of } \\
\text { Fy(N) }\end{array}$ \\
\hline
\end{tabular}

\begin{tabular}{|c|c|c|c|c|c|c|c|c|c|c|c|c|c|c|}
\hline & & & & & \\
\hline & & & & & $\bar{F}$ & $\bar{V}$ & $\bar{F}$ & $\bar{V}$ & $\bar{F}$ & $\bar{V}$ & $\bar{F}$ & $\bar{V}$ & $\bar{F}$ & $\mathrm{~V}$ \\
\hline 1 & 10000 & 0.1 & 0.2 & 10 & 19.1 & 20.4 & 8.7 & 12.1 & 166.8 & 192.5 & 5.2 & 4.6 & 1.1 & 7.2 \\
\hline 2 & 10000 & 0.1 & 0.2 & 20 & 18.6 & 20.2 & 8.6 & 16.3 & 155.5 & 190.3 & 6.2 & 6.1 & 1.4 & 13.4 \\
\hline 3 & 10000 & 0.1 & 0.2 & 30 & 18.4 & 20.1 & 8.4 & 19.5 & 148.4 & 187.4 & 8.0 & 8.0 & 2.0 & 21.3 \\
\hline 4 & 10000 & 0.1 & 0.2 & 40 & 15.0 & 19.0 & 7.5 & 21.6 & 141.6 & 192.6 & 9.1 & 8.7 & 3.2 & 26.2 \\
\hline 5 & 10000 & 0.1 & 0.2 & 50 & 12.5 & 18.7 & 6.0 & 23.5 & 135.0 & 200.2 & 9.5 & 9.5 & 4.0 & 30.5 \\
\hline 6 & 10000 & 0.1 & 0.2 & 60 & 10.5 & 17.8 & 5.4 & 24.2 & 132.8 & 213.2 & 10.3 & 9.8 & 4.6 & 35.6 \\
\hline 7 & 10000 & 0.1 & 0.2 & 70 & 9.8 & 17.6 & 4.6 & 25.6 & 130.3 & 224.3 & 11.2 & 10.2 & 5.4 & 38.6 \\
\hline 8 & 10000 & 0.1 & 0.2 & 80 & 8.6 & 17.0 & 4.2 & 26.0 & 128.6 & 240.5 & 11.3 & 10.3 & 5.8 & 38.9 \\
\hline 9 & 10000 & 0.1 & 0.2 & 90 & 8.2 & 16.6 & 4.0 & 26.5 & 125.2 & 245.2 & 12.0 & 10.6 & 6.2 & 40.5 \\
\hline 10 & 10000 & 0.1 & 0.2 & 100 & 7.2 & 16.5 & 3.3 & 27.2 & 120.3 & 255.3 & 13.2 & 11.2 & 7.1 & 40.8 \\
\hline
\end{tabular}

F --- Applying Feed direction vibration; v--- Applying Vertical feed direction vibration 
(a)

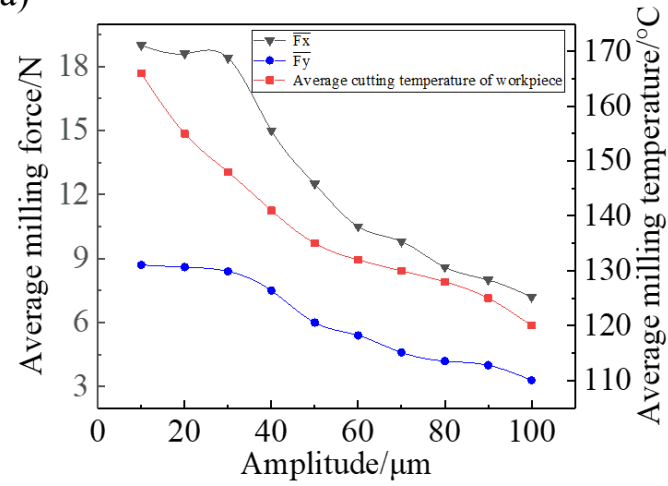

(c)

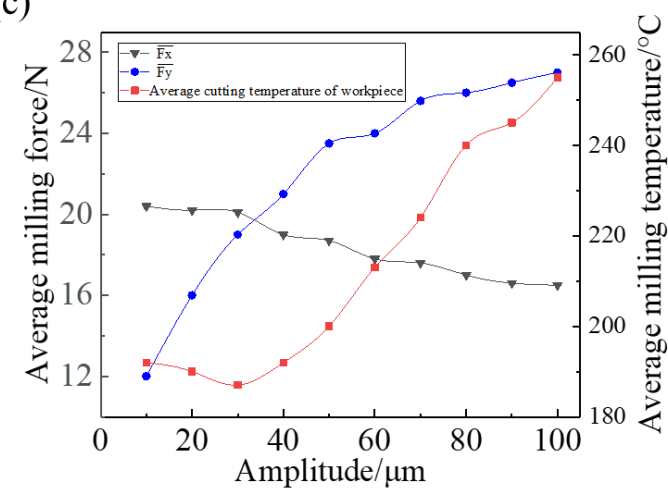

(b)

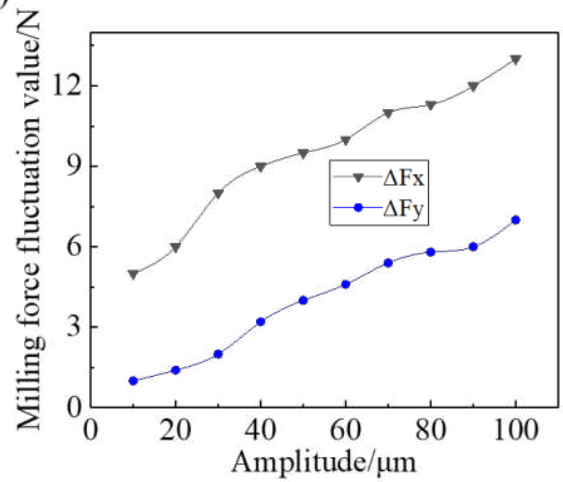

(d)

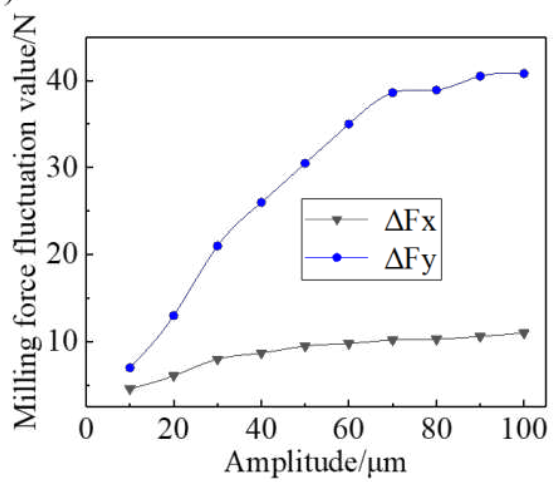

Figure 11 Effect of amplitude $(20 \mathrm{kHz})$ on average milling force, temperature, and milling force fluctuations: (a) Average milling force and temperature applying feed direction vibration,(b) Milling force fluctuation value applying feed direction vibration,(c) Average milling force and temperature applying vertical feed direction vibration,(d) Milling force fluctuation value applying vertical feed direction vibration

\section{Conclusion}

In this paper, a simulation method of milling considering process vibration is presented by taking the undeformed chip thickness into account, and the effectiveness of the simulation method and model are verified by milling experiments. The influence of vibration parameters on milling performance is studied by using the simulation model. According to the analysis results, the following conclusions are drawn as follow:

(1) Based on the theory of unformed chip thickness in the milling process, a simulation method of unformed chip thickness considering vibration was proposed. The machining performance under different vibration parameters can be studied with the proposed model.

(2) The experimental tests are performed to verify the simulation method and model, and the results show that the effectiveness of the FEM models in predicting the milling force and milling temperature. Therefore, the simulation model can define the influence of milling vibration on machining quality and can be applied to distinguish the favorable and unfavorable vibration parameters.

(3) The influence of vibration frequency on milling force and temperature was studied by the simulation model. The results indicate that the tool vibration can effectively decrease the average milling force and temperature at ultrasonic frequency, but at the same time it increases the 
fluctuation degree of milling force. Therefore, it is important to choose the vibration frequency in vibration-assisted process.

(4) When low frequency vibration in the vertical feed direction is applied, increasing the vibration amplitude will result in the increase of the average milling force, temperature and milling force fluctuation values, which adversely affects the machining quality. When the ultrasonic vibration in the feed direction is applied, increasing the amplitude would reduce the average milling force and temperature, but increase the milling force fluctuation value.

\section{Acknowledge}

\section{Funding information}

This project is supported by The National Natural Science Foundation of China ( No.51905347 )

\section{Ethical Approval}

Compliance with ethical standards.

\section{Consent to Participate and Publish}

\section{Conflict of interest}

The authors declare that they have no conflict of interest.

\section{Authors Contributions}

Miaoxian Guo: Conceptualization, Methodology, Writing. Jianming Wang: Data curation, Original draft preparation. Weicheng Guo: Methodology, Editing, Corresponding.

Jin Liu: Visualization, Investigation.

Xiaohui Jiang: Supervision, Reviewing.

\section{Availability of data and materials}

The data and materials that support the findings of this study are available from the corresponding author upon reasonable request.

\section{Reference}

[1] Li H, Wu B (2016) Development of a hybrid cutting force model for micromilling of brass. International Journal of Mechanical Sciences 115-116:586-595.

[2] Zhang F, Wang Q, Yang R (2014) Analysis to Milling Force Base on AdvantEdge Finite Element Analysis. Advanced Materials Research 981:895-898.

[3] Peng B, Li X, Wang X, Mo J, Luo L (2021) Simulation study on temperature field and microstructure of Ti-6Al-4V alloy round ingot during EBCHM. Materials Research Express 8:046505.

[4] Guo M, Ye Y, Jiang X, Wu C (2020) Comprehensive effect of multi-parameters on vibration in high-speed precision milling. The International Journal of Advanced Manufacturing Technology 108:2187-2195. 
[5] Guo W, Wu C, Ding Z, Zhou Q (2021) Prediction of surface roughness based on a hybrid feature selection method and long short-term memory network in grinding. The International Journal of Advanced Manufacturing Technology 112:2853-2871.

[6] Zhu D, Feng X, Xu X, Yang Z, Li W, Yan S, et al (2020) Robotic grinding of complex components: A step towards efficient and intelligent machining - challenges, solutions, and applications. Robotics and Computer-Integrated Manufacturing 65:101908.

[7] Li C, Li X, Huang S, Li L, Zhang F (2021) Ultra-precision grinding of Gd3Ga5O12 crystals with graphene oxide coolant: Material deformation mechanism and performance evaluation. Journal of Manufacturing Processes 61:417-427.

[8] Shtehin O, Seguy S, Wagner V, Landon Y, Dessein G, Mousseigne M (2018) Low-frequency chatter genesis during inclined surface copy-milling with ball-end mill: Experimental study. Machining Science and Technology 22:621-637.

[9] Kecik K, Rusinek R, Warminski J (2012) Modeling of high-speed milling process with frictional effect. Proceedings of the Institution of Mechanical Engineers, Part K: Journal of Multibody Dynamics 227:3-11.

[10] Liu Y, Wang Z, Liu K, Zhang Y (2016) Chatter stability prediction in milling using timevarying uncertainties. The International Journal of Advanced Manufacturing Technology 89:26272636.

[11] Yang Z, Zhu L, Zhang G, Ni C, Lin B (2020) Review of ultrasonic vibration-assisted machining in advanced materials. International Journal of Machine Tools and Manufacture 156:103594.

[12] Huang Y, Jiahua S, Xiao G, He Y, Dai W, He S, Li W(2020). Study on the surface topography of the vibration-assisted belt grinding of the pump gear. The International Journal of Advanced Manufacturing Technology 106, 719-729.

[13] Verma GC, Pandey PM (2019) Machining forces in ultrasonic-vibration assisted end milling. Ultrasonics 94:350-363.

[14] Elhami S, Razfar MR, Farahnakian M (2015) Analytical, numerical and experimental study of cutting force during thermally enhanced ultrasonic assisted milling of hardened AISI 4140. International Journal of Mechanical Sciences 103:158-171

[15] Kong C, Wang D (2018) Numerical investigation of the performance of elliptical vibration cutting in machining of AISI 1045 steel. The International Journal of Advanced Manufacturing Technology 98:715-727.

[16] Chen W, Zheng L, Teng X, Yang K, Huo D (2019) Finite element simulation and experimental investigation on cutting mechanism in vibration-assisted micro-milling. The International Journal of Advanced Manufacturing Technology 105:4539-4549.

[17] Tao G, Ma C, Shen X, Zhang J (2016) Experimental and modeling study on cutting forces of feed direction ultrasonic vibration-assisted milling. The International Journal of Advanced Manufacturing Technology 90:709-715.

[18] Feng Y, Hsu F, Lu Y, Lin Y, Lin C, Lin C, et al (2020) Temperature prediction of ultrasonic vibration-assisted milling. Ultrasonics 108:106212.

[19] Lu D, Huang H, Wu Y, Yang M (2012) Finite Element Analysis for Ti-6Al-4V in UltrasonicVibration-Assisted Micro-Cutting. Advanced Materials Research 500:345-350.

[20] Luo H, Wang Y, Zhang P (2020) Effect of cutting and vibration parameters on the cutting performance of 7075-T651 aluminum alloy by ultrasonic vibration. The International Journal of 
Advanced Manufacturing Technology 107:371-384.

[21] Verma GC, Pandey PM, Dixit US (2018) Estimation of workpiece-temperature during ultrasonic-vibration assisted milling considering acoustic softening. International Journal of Mechanical Sciences 140:547-556.

[22] Jiang X, Li B, Yang J, Zuo X, Li K (2012) An approach for analyzing and controlling residual stress generation during high-speed circular milling. The International Journal of Advanced Manufacturing Technology 66:1439-1448.

[23] Johnson GR, Cook WH (1985) Fracture characteristics of three metals subjected to various strains, strain rates, temperatures and pressures. Engineering Fracture Mechanics 21:31-48.

[24] Jung J-W, Lee SE, Hong J-W (2019) Experimental and Numerical Investigations of HighSpeed Projectile Impacts on 7075-T651 Aluminum Plates. Materials 12:2736.

[25] Rice JR, Tracey DM (1969) On the ductile enlargement of voids in triaxial stress fields*. Journal of the Mechanics and Physics of Solids 17:201-217. 